\title{
Intervenção psicológica e prevenção da saúde mental na relação mãe-criança*
}

\author{
Claudete Marcon ${ }^{I}$ \\ Lecila Duarte Barbosa Oliveira \\ Viviane Vieira \\ Universidade Federal de Santa Catarina
}

\section{Resumo}

Após o nascimento do bebê os processos de simbiose e posteriormente de individuação são importantes para o desenvolvimento adequado da criança em todos os âmbitos da saúde. Obstáculos podem atrapalhar esse desenvolvimento, como a saúde mental da mãe ou do cuidador. Esse trabalho provém de uma intervenção psicológica em uma enfermaria pediátrica com uma mãe de 21 anos e seu filho de 1 ano e 5 meses. Durante as internações da criança, foi possível observar que a mãe apresentava dificuldades em lidar com o processo de individuação da criança. Além disso, a mãe verbalizava sua dependência excessiva em relação à criança, sentindo-se culpada e com ideação suicida. Os atendimentos psicológicos focaram na orientação da mãe sobre as conseqüências dessa relação no desenvolvimento de seu filho e na sensibilização da mesma para o atendimento psicológico após a alta hospitalar. Com isso, a intervenção envolveu além do tratamento imediato, a prevenção da saúde mental da criança.

Palavras-chave: Relação mãe e bebê; simbiose-individuação; prevenção saúde mental; intervenção psicológica.

\begin{abstract}
After the birth of the baby the processes of symbiosis and later of individuation are important for the proper development of children in all areas of health. Obstacles that may hinder development as the mental health of the mother or caregiver. This work comes from a psychological intervention in a pediatric ward with a mother of 21 years and his son of 1 year and 5 months.

\footnotetext{
"Psychological intervention and prevention of mental health in mother-child relationship

' Endereço para correspondências: Rua Bocaiúva, $n^{\circ} 1659$, apartamento 1001, Centro, Florianópolis, SC, 88015-530 (viviane1105@yahoo.com.br).
} 
During the hospitalizations of children, it was possible to observe that the mother had difficulties in dealing with the process of individuation of the child. Moreover, the mother refers excessive dependence with regard to the child feeling guilty and with suicidal ideation. The intervention focused on the psychological orientation of the mother about the consequences of that relationship in the development of your child and raising awareness of it to the psychological care after discharge from hospital. With this, the intervention involved beyond the immediate treatment, prevention of mental health of the children.

Keywords: Mother-baby relation; symbioses-individuation; mental health prevention; psychological intervention.

$\mathrm{O}$ s cuidados com a criançą não iniciam somente no nascimento. $O$ processo de vinculação se constrói lentamente, envolvendo o planejamento e também todos os sentimentos, expectativas dos pais durante a gravidez (BORGES, 2005). E para que esse processo ocorra de forma saudável é necessário envolvimento e participação ativa dos progenitores ou cuidadores, proporcionando um ambiente saudável e adequado para a vinda da criança (WINNICOTT, 1955/1991).

Para a criança, a presença materna é extremamente valorizada e necessária, assim como a presença paterna faz-se também de valor (BORGES, 2005). Durante a gravidez, a mulher sente a criança se desenvolvendo e sofre as mudanças, de ordem física e emocional, vividas normalmente com muita intensidade. Especialmente no final da gravidez, a mulher normalmente adquire sensibilidade e a capacidade particular de se identificar com as necessidades do bebê. Esse estado psicológico especial é chamado de "preocupação materna primária". Esse termo cunhado por Winnicott(1955/1993) é o que capacita a mãe a realizar os cuidados iniciais com a criança (BLEICHMAR \& BLEICHMAR, 1992).

Uma das etapas seguintes após essa preocupação é o holding, ou seja, a sustentação materna para a criança. Termo também proposto por Winnicott (1955/1993), o holding envolve a sustentação física, sensibilidade epidérmica da criança, sensibilidade auditiva e visual (BLEICHMAR \& BLEICHMAR, 1992; WINNICOTT, 1955/1993). Esse momento inclui toda a rotina dos cuidados físicos e de um ambiente mais seguro possível. Durante esta fase, também estão implicados todos os cuidados com o desenvolvimento emocional. 
Intervenção psicológica e prevenção da saúde mental na relação mãe-criança Claudete Marcon, Lecila Duarte Barbosa Oliveira e Viviane Vieira

A criança necessita sentir-se amada e protegida e o cuidador precisa agir como um ego auxiliar enquanto a criança ainda não consegue desenvolver suas capacidades inatas de síntese e integração (BLEICHMAR \& BLEICHMAR, 1992; WINNICOTT, 1955/1993). Quando a criança encontra um ambiente seguro, que transmita afeição, é mais provável que desenvolva ao máximo suas capacidades mentais, físicas, sociais e afetivas.

Essa atmosfera de segurança possibilita que a criança alcance e mantenha proximidade com outra pessoa claramente identificada como mais apta a lidar com o mundo. Segundo Bowlby (1989), este vínculo que a criança estabelece com o cuidador favorece que ela se torne mais capaz para desenvolver suas habilidades sociais e mais segura para explorar o mundo exterior, uma vez que encontra tranqüilidade de voltar para um ambiente onde será confortada e encorajada (MONDARDO \& VALENTINA, 1998).

O momento inicial após o nascimento o bebê necessita de cuidados especiais, tanto de ordem física como emocional. A proximidade que a mãe mantém com a criança é compreendida como simbiótica, uma vez que o infante ainda não se reconhece como um indivíduo separado da mãe e esta sente as necessidades do bebê como suas (MAHLER, 1983; WINNICOTT, 1955/1993). Essa simbiose inicialmente é saudável e pré-requisito para que a fase seguinte, da individuação, ocorra tranquilamente (MAHLER, 1983).

Mahler (1983) relata que o a fase da separação-individuação inicia-se entre os 12 e 18 meses. Nesse período, a criança demonstra os avanços motores e o ambiente externo se mostra interessante e estimulante à exploração. Com isso, a criança inicia os avanços para o mundo exterior, procurando outras fontes de prazer e gratificação, contudo, esse processo é lento. Assim como a simbiose, a individuação é um processo crescente que envolve adaptação da mãe e do bebê para esse novo momento, é possível que a mãe apresente dificuldades no desvincular da criança, sentindo-se rejeitada e deixada de lado. Entretanto, num processo de desenvolvimento saudável, esses sentimentos maternos não geram atos superprotetores ou sofrimentos intensos, pois a mãe compreende e até estimula a autonomia do infante.

$\mathrm{Na}$ individuação, a criança consegue preencher o espaço vazio entre ela e o corpo da mãe com o mundo exterior, tornando-se um bom momento para o desmame (BARBIERI; JACQUEMIM \& ALVES, 2005). É importante ressaltar que a criança ainda necessita da orientação e presença da mãe, pois a separação-individuação não é um movimento constante, ele envolve momentos de afastamento exacerbado e volta para a simbiose materna. 
Segundo Mahler(1983), normalmente esse momento perdura até os 36 meses.

Para que a criança e a mãe transitem por essas fases de maneira saudável alguns fatores precisam ser explicitados. Inicialmente, é necessário que as fases que antecedem cada um desses momentos sejam vividas tranquilamente, ou seja, para que a individuação ocorra, é importante que a simbiose tenha sido vivida e antes disso toda a preparação da gravidez tenha acontecido (MAHLER, 1983). Além disso, as vivências que a mãe teve como filha são importantes, pois a maneira que os cuidados parentais foram sentidos pela pessoa reflete no modo que a mesma exercerá sua parentalidade mais tarde (BORGES, 2005; CARTER ; MCGOLDRICK, 2001). Caso a mãe tenha vivenciado uma simbiose-individuação adequada quando criança, possivelmente ela irá repetir a experiência no papel de mãe. Porém, o contrário também é possível, pessoas que sofreram durante essas fases podem apresentar dificuldades importantes quando no exercício dos cuidados parentais (ALT \& BENETTI, 2008; BORGES, 2005; CARTER \& MCGOLDRICK, 2001; MAHLER, 1983).

Além das vivências ruins quando criança, outros dificultadores podem se apresentar durante as fases de simbiose-separação. Patologias maternas como depressão (pós-parto ou crônica), psicoses e transtornos limítrofes estão intimamente relacionadas com dificuldades nesses momentos. Outros fatores como falta de suporte social, baixo apoio do parceiro, dificuldades financeiras e problemas de saúde da criança também são trazidos como possíveis obstáculos para o sucesso das fases de simbiose e individuação (ALT \& BENETTI, 2008; BORGES, 2005; MAHLER, 1983). Com essas dificuldades, a mãe pode apresentar um apego excessivo durante a simbiose ou um problema de vinculação com o bebê. Já na individuação, a mãe pode emitir comportamentos de negligência, não oferecendo segurança para a criança ou não permitindo que esta se desvincule dela, reprimindo qualquer comportamento de autonomia que seu filho apresente (MAHLER, 1983).

Quando a mãe apresenta tais dificuldades, as conseqüências para a criança podem ser diversas, como problemas comportamentais futuros, déficit nos relacionamentos interpessoais, tanto para estabelecer novos laços afetivos como para mantê-los, maior probabilidade de adoecer, além de prejudicar o modo de exercer sua futura parentalidade (ALT \& BENETTI, 2008; BORGES, 2005; CARTER \& MCGOLDRICK, 2001; MAHLER, 1983). Essas conseqüências provêm de um momento bem inicial do desenvolvimento, 
Intervenção psicológica e prevenção da saúde mental na relação mãe-criança

Claudete Marcon, Lecila Duarte Barbosa Oliveira e Viviane Vieira

porém de vital importância para a pessoa durante toda a sua vida (BLEICHMAR \& BLEICHMAR, 1992; BORGES, 2005; MAHLER, 1983; WINNICOTT, 1955/1993).

Por se tratar de um período essencial para a saúde mental das crianças, a intervenção do psicólogo mostra-se fundamental durante as fases iniciais da relação mãe e bebê. Nesse caso, o profissional psicólogo pode verificar as dificuldades apresentadas na vinculação ou na desvinculação da mãe com sua criança, buscando identificar quais os fatores envolvidos. Quando dificuldades são percebidas, é possível trabalhar com a mãe aspectos, tais como: conhecimento a respeito de sua infância, suas experiências iniciais, a dinâmica familiar e a rede de suporte social percebida. Além disso, é importante um olhar atento sobre possíveis diagnósticos como depressão, estados limítrofes e psicoses que a mãe pode apresentar.

Como nesse início do desenvolvimento é comum a presença em centros de saúde, especialmente em decorrência da rotina de consultas ao pediatra, vacinas e pequenas doenças da infância, faz-se importante os profissionais da saúde ficarem atentos aos sinais de dificuldades entre a mãe e o bebê. Em razão dos aspectos psicológicos envolvidos no processo de vinculação e individuação mãe-bebê, justifica-se a inserção do psicólogo nos serviços de saúde, independentemente do nível de atenção, buscando identificar e acompanhar essas famílias desde o início, incluindo a gravidez ou mesmo o planejamento familiar.

Esse artigo é um relato da intervenção psicológica em uma enfermaria pediátrica com uma mãe que apresentava dificuldades no processo simbiose e individuação com seu filho.

\section{Relato do caso clínico}

O caso analisado é de uma criança, Bernardo ${ }^{2}$, do sexo masculino, com um ano e cinco meses de idade na última hospitalização. A criança foi internada na ala pediátrica de um hospital escola duas vezes no ano de 2008, sendo que a primeira teve duração de 17 dias e a segunda, dois meses depois, permanecendo cinco dias. Em ambas as situações a queixa principal foi pneumonia. Durante as duas hospitalizações, a família foi acompanhada pelo serviço de psicologia presente na enfermaria pediátrica.

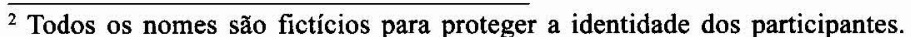




\section{HüMANAS}

Bernardo foi acompanhado durante as internações pela mãe, Fabiana, de 21 anos. Esta se encontrava desempregada, era solteira e havia cursado até o ensino médio. A mãe referia que o relacionamento com o pai de Bernardo era difícil, sendo que logo após seu nascimento houve o rompimento, e este não registrou a criança. Relatou ainda que seu ex-companheiro era violento, com relações no tráfico de drogas. Nos momentos das internações, segundo Fabiana, o pai por ordem judicial estava impedido de se aproximar dela ou da criança e não disponibilizava nenhuma ajuda financeira. A mãe argumentava: "prefiro não receber nenhuma ajuda a ter que falar com ele".

A relação com o pai da criança é relatada por Fabiana como conturbada desde o início e com a gravidez afirmava ter piorado consideravelmente, dizia que a criança não era dele e se negava a assumi-la e registrá-la. Contudo, o nome da criança foi escolhido pelo pai - uma homenagem ao avô paterno - e acatado por Fabiana, apesar da mesma referir que já imaginava o fim do relacionamento. Ainda refere "fui uma idiota! Sabia que a gente não tinha nada a ver, mas fui lá e coloquei (o nome de Bernardo). E eu odeio esse nome".

Fabiana relatou durante os atendimentos que a gravidez de Bernardo foi complicada devido ao relacionamento amoroso. Segundo ela, o pai de Bernando freqüentemente lhe batia e discutia agressivamente. Apesar disso, a gravidez transcorreu sem problemas de saúde, com o parto natural, porém "extremamente doloroso", com o curso do tempo normal.

Logo após o nascimento, mãe e filho voltaram para a casa, juntamente com o pai. Segundo Fabiana, a volta para a casa com a criança e os primeiros meses seguintes foram repletos de brigas, com episódios de violência física contra ela e o bebê. Fabiana argumenta que "depois que ele machucou meu filho não teve mais volta. Ai fui morar com a minha mãe e o denunciei. Finalmente me livrei da praga".

Relata muitas dificuldades também com a mãe, informou que sua relação com ela já era conflituosa desde a adolescência. Fabiana afirma que foi morar sozinha logo após terminar o ensino médio, pois não dava "certo" com a mãe. Refere que ambas brigavam e implicavam muito "uma com a outra". Segundo Fabiana, sua mãe a colocou no psicólogo quando tinha uns 12 ou 13 anos por que "era esquentada", com ímpetos de violência. Lembra somente de ter feito desenhos e histórias bobas durante os atendimentos psicológicos recebidos nessa época. 
Intervenção psicológica e prevenção da saúde mental na relação mãe-criança Claudete Marcon, Lecila Duarte Barbosa Oliveira e Viviane Vieira

Com a volta de Fabiana ao lar materno, segundo a mesma as brigas voltaram e sua mãe passou a interferir demais na criação de Bernardo, esta desvalorizava seu papel de mãe e freqüentemente agia com a criança de forma contrária a qual ela desejava. Em razão disso, Fabiana e a criança logo se mudaram e passaram a morar sozinhos desde então, em uma casa de madeira em uma comunidade de alto risco.

Segundo relato de Fabiana, desde que passaram a morar sozinhos a relação com a criança é de extrema proximidade. Dormem na mesma cama, ele está sempre grudado nela, buscando sua atenção o tempo todo. A mãe refere que a criança tem dificuldades em se afastar dela e quase não fica com ninguém, relatou que ficava muito cansada e, em razão de também precisar trabalhar, colocou a criança com seis meses na creche. Porém segundo ela a criança ainda permanece muito próxima, mesmo com a creche e busca sua presença excessivamente.

A mãe referiu durante os atendimentos que a criança ainda exigia muita atenção dela, freqüentemente demandava cuidados. Contudo, Fabiana mostrou dificuldades com alguns comportamentos de autonomia do filho, como quando relatou que foi buscá-lo na creche e este demonstrou não querer ir, fechando a porta da sala com força, deixando-a do lado de fora, ela argumentou que ficou muito magoada com a criança, especialmente por que $o$ fato ocorreu próximo ao dia das mães.

Houve vários momentos durante a internação que Fabiana relatava que não agüentava mais ficar perto da criança, porém quando alguém se oferecia para cuidar da criança, a mãe relutava em sair de perto. Nas vezes que Fabiana se afastava da criança, a mesma ficava tranqüila e ativa. Nesses momentos a mãe não se afastava da criança por muito tempo, permanecendo no máximo por cinco minutos longe. Quando questionada o porquê de voltar rapidamente, esta respondia que Bernardo não conseguia ficar longe dela, apesar da criança apresentar-se tranqüila.

A mãe por diversas vezes emitia comportamentos ambíguos, xingava e provocava a criança até esta chorar, logo em seguida abraçava-a e beijava-a. Relatava que seu filho era o grande responsável por sua tristeza do momento, pois ele tirava tudo dela, inclusive empregos e a diversão. Após um atendimento focando na inconstância de seus comportamentos com a criança, Fabiana relatou que "ter filho cansa. As pessoas não falam sobre isso. Dizem que é muito lindo e realmente é. Mas é muito cansativo também!". 


\section{HUMANAS}

Com o acolhimento desse discurso Fabiana referiu que às vezes tinha vontade de fugir de casa e deixar a criança lá dentro. Ao mesmo tempo, relatava que Bernardo era a única pessoa que mantinha a sua vontade de viver, pois freqüentemente pensava em suicídio. Contudo, grande parte do desejo de tirar a própria vida provinha do cansaço e estresse que a criança lhe causava, ou seja, nesse momento Fabiana demonstrava muita ambigüidade em relação aos sentimentos para com a criança.

Outro ponto importante foi o relato de Fabiana sobre como agia com Bernardo quando ficava nervosa: "Ele me estressa muito, sabe. Ás vezes eu judio, machuco ele. Não é espancar assim, mas eu judio. Vem de dentro de mim uma raiva...". Fabiana referia que nesses momentos de incômodo com a criança, a beliscava ou dava tapas na bunda. Muitas vezes saia de casa, fechava a porta e ficava ouvindo seu choro por alguns minutos. Após esses episódios, relatava arrependimento e freqüentemente pedia desculpas à criança.

Fabiana procurou ajuda psicológica após a primeira internação, em sua Unidade Básica de Saúde de referência. Contudo, a única intervenção psicológica disponível naquele momento era em grupo e ela relatou não gostar de grupos, pois, “as mulheres mais fofoqueiras do bairro vão nesses grupos só pra ficar sabendo da vida dos outros. Eu não vou contar minhas coisas lá e todo mundo ficar sabendo. Essa coisa de grupo não dá certo comigo".

A partir do relato acima, será apresentada a intervenção psicológica e serão discutidos os fatores envolvidos nas dificuldades enfrentadas por Fabiana.

\section{Discussão}

A preocupação materna primária e o holding são momentos que a mãe necessita se voltar para o bebê. No primeiro, a mãe sente a criança se desenvolvendo em sua barriga, os sintomas da gravidez e o que o bebê está precisando ou sentindo dentro dela. Após o parto, essa preocupação atinge seu ápice, e diminui à medida que a criança cresce. No holding, a mãe fornece à criança tantos os cuidados físicos, como sustentação no colo, comida, ambiente seguro; como também cuidados emocionais, carinho, proteção e segurança (BLEICHMAR \& BLEICHMAR, 1992; WINNICOTT, 1955/ 1993). Esses períodos são essenciais para o desenvolvimento do bom vínculo com a criança e mais tarde do apego (MONDARDO \& VALENTINA, 1998). 
No caso de Fabiana, a vivência no final da gravidez, assim como no pós-parto foi dificil e repleta de agressões e momentos conturbados. Seu excompanheiro abusava fisicamente com freqüência dela e algumas vezes até mesmo da criança. $O$ ambiente não era seguro e saudável tanto para a mãe como para o bebê, assim, ambos não puderam vincular adequadamente já nesse período inicial. Após as agressões freqüentes, Fabiana separou-se do pai de Bernardo quando este tinha dois meses, devido à conturbação do momento, provavelmente não teve tempo para vivenciar o luto da separação e prestar atenção em suas sensações e necessidades, assim como para as do bebê, o que dificultou a desenvolver sua função materna primária e o holding, pois a mãe necessita voltar sua atenção para si mesma e para a criança, tentando compreender e redirecionar suas emoções (BLEICHMAR \& BLEICHMAR, 1992; WINNICOTT, 1955/1993). Dessa forma, o vínculo com a criança e a simbiose da relação ficou comprometido, e isto possivelmente refletiu também na fase da individuação.

Bernardo encontrava-se no processo de individuação, pois começava e emitir comportamentos de autonomia emocional e motora (LOPES et al., 2007). Contudo, esse movimento de separação não é contínuo, a criança oscila em momentos de distanciamento e simbiose (MAHLER, 1983). Dificuldades parentais, especialmente maternas, são esperadas, entretanto, sem que a criança seja inibida ou repreendida severamente em seus comportamentos de autonomia (LOPES et al., 2007; MAHLER, 1983).

Neste caso, Fabiana apresentou dificuldades na simbiose. Etapas anteriores são pré-requisitos para o desenvolvimento das etapas posteriores, ou seja, uma simbiose não vivenciada prejudica ou mesmo impede a individuação (MAHLER, 1983). Além disso, Fabiana emitia também comportamentos ambíguos para com a criança, oscilando entre superproteção e abandono. Como relatado anteriormente, era comum a mãe não querer que Bernardo fosse afastado dela, porém quando a criança estava por perto, frequentemente desvalorizava sua presença ou negligenciava as aproximações. Fabiana não estava disponivel nem física nem emocionalmente, pois quando estava presente não participava das explorações da criança e não se empenhava em organizar o ambiente para Bernardo, o que é esperado pelos pais no momento de individuação (LOPES et al., 2007; MAHLER, 1983).

A intervenção da psicologia nesse momento foi apontar para a mãe seus comportamentos ambíguos e o reflexo deles no filho, assinalando que este ficava confuso não compreendendo o que ela desejava dele. 
Essa insegurança e instabilidade na relação de ambos poderiam gerar diversas conseqüências em Bemardo, como problemas emocionais e psicopatologias graves (ALT \& BENETTI, 2008; BORGES, 2005; MAHLER, 1983). Fabiana relatava saber de suas dificuldades na autonomia da criança e pontuava também muito incômodo com a simbiose de Bernardo. Frequentemente relatava que ser mãe não era tranquiilo, que exigia muito dela, ocupando toda sua rotina.

Quando Fabiana relatava episódios de cansaço e irritação nas atividades maternas, seu discurso era acolhido e assinalado que ser mãe não é algo que nasce naturalmente, mas sim que exige um envolvimento, adaptação e tolerância que se desenvolvem através das vivências com a criança (BORGES, 2005; LOPES et al., 2007; WINNICOTT,1955/1993). Foi pontuado ainda para Fabiana que ser mãe exigia também muitas responsabilidades e que sua relação com Bernardo é de extrema importância para o seu desenvolvimento saudável.

A partir do cansaço e falta de apoio social que Fabiana relatava, por não ter com quem dividir os cuidados necessários a Bernardo, conversar, ou se divertir, a intervenção psicológica foi de procurar redes de apoio alternativas ou negligenciadas por ela. Foi reavaliada a sua rotina, e procuradas possibilidades de ajuda junto ao seu circulo de amigos e vizinhos para auxiliá-la nas tarefas diárias e amenizar as suas situações de estresse. Com a lembrança de alguns nomes de pessoas que poderiam estar disponíveis, Fabiana ainda pontua que o lazer e outras atividades sociais iriam ser de grande valia para ela e para a criança. A presença de outras pessoas ou outras atividades contribuem para o afastamento saudável entre mãe e criança, pois a falta desses exacerba comportamentos simbióticos (BORGES, 2005; LOPES et al., 2007). Assim, a rede de apoio tornar-se-ia um fator de proteção para a mãe e para a criança $e$ dessa forma Fabiana teria oportunidades de desenvolver outras atividades e consequentemente aceitar melhor a individuação de Bernardo.

Outra preocupação foi encaminhar Fabiana para o serviço social presente na pediatria do Hospital, com o intuito de investigar vagas de emprego e cursos gratuitos. Fabiana encontrava-se desempregada no momento da segunda internação e relatava muito incômodo com sua situação financeira. Para tornar um trabalho mais eficaz, é importante verificar outras demandas da paciente e mobilizar os diversos profissionais presentes na instituição, respeitando as especificidades de cada profissão. A relação com outros membros da equipe de saúde fortalece o trabalho do psicólogo enriquece as atuações, pois o trabalho multidisciplinar contribui com intervenções mais plenas (PENNA, 1992). 
Fabiana indica a mãe como uma das pessoas que poderiam lhe oferecer suporte e ajuda, vale lembrar que ela foi morar com esta após a separação. Contudo, Fabiana refere que o relacionamento entre ambas sempre foi repleto de conflitos. Reporta-se a ela como controladora e o avô como ausente. Durante a adolescência mãe e filha brigavam muito, resultando em fuga da casa materna aos 17 anos, assim, ficou morando pouco tempo com a mãe. Essas dificuldades na vivência como filha é um indicativo na dificuldade que Fabiana tem como mãe, pois o modo como vivemos os cuidados parentais refletem no modo como exercemos nossa parentalidade (ALT \& BENETTI, 2008; BORGES, 2005; CARTER \& MCGOLDRICK, 2001).

Fabiana apresentava também um histórico de "explosões emocionais" (sic). Segundo ela tinha ímpetos de raiva e isso preocupava a sua mãe, quando ainda adolescente esta a levou para atendimento psicológico. Referia que os episódios de explosões eram freqüentes, e que estes ainda ocorriam no seu cotidiano, atualmente. Relatava também muitos sentimentos de isolamento e tristeza, com ocorrência de ideação suicida. Todos esses sintomas indicam a possibilidade de uma psicopatologia, contudo devido a intervenção rápida e focal que o contex to hospitalar exige (PENNA, 1992), não foi possível precisar um diagnóstico. Apesar da ausência de uma análise mais preci$\mathrm{sa}$, era evidente sofrimento intenso e angustia enquanto esta relatava os fatos.

As psicopatologias maternas prejudicam todo vínculo com a criança $\mathrm{e}$ no movimento simbiose-individuação, pois o sofrimento psíquico impede que a mãe vivencie de maneira saudável as fases da maternidade (ALT \& BENETTI, 2008; LOPES et al., 2007; MAHLER, 1983).

Em outra oportunidade, Fabiana já havia procurado ajuda psicológica e o atendimento ocorreu em grupo, esta não aderiu à terapia, alegando que receava perder sua individualidade e o respeito dos integrantes do grupo, uma vez que não se sentia à vontade de compartilhar com pessoas da comunidade seus problemas. Foi então encaminhada para o atendimento psicológico individual, nessa ocasião foi ressaltada a urgência da intervenção e a necessidade de tratamento contínuo. $\mathrm{O}$ acompanhamento psicológico e/ou psiquiátrico mostram-se úteis como ferramentas para o fortalecimento e instrumentalização materna, para que as mães possam sentir-se mais capacitadas e saudável em sua atuação (ALT \& BENETTI, 2008).

A atuação do profissional da psicologia no presente caso visou, além de amenizar o sofrimento da mãe, a prevenção da saúde mental de Bernardo. 
Os riscos para a criança iam além dos físicos, pois Fabiana com freqüência oscilava seu comportamento e apresentava dificuldades em fornecer-lhe um ambiente seguro e adequado emocionalmente. Assim, as conseqüências poderiam ser diversas, incluindo o prejuízo no desenvolvimento cognitivo, afetivo e das relações interpessoais (MAHLER, 1983; BORGES, 2005; ALT \& BENETTI, 2008). Além disso, Bernardo poderia repetir essa relação através da transgeracionalidade, visto que as vivências da dinâmica familiar se perpetuam por várias gerações (CARTER \& MCGOLDRICK, 2001). A prevenção então se torna necessária para que esse ciclo de cuidados possa ser modificado para atuações parentais mais benéficas e promotoras de saúde. Portanto, o papel do psicólogo nesse contexto hospitalar é de promover saúde e prevenir doenças, superando assim a função inicial somente curativa quando da inserção nos serviços de saúde pública (CARDOSO, 2002; RUTSATZ \& CÂMARA, 2006).

\section{Considerações Finais}

A intervenção nesse caso foi no início do processo de individuação da criança. Contudo, a prevenção e atuação podem ocorrer em momentos anteriores a este, como no planejamento familiar e durante a gravidez. Quanto mais cedo for a intervenção, maior a probabilidade de sucesso e mais variedade de atuações são possíveis (MURTA, 2007). Portanto, faz-se necessário uma equipe multiprofissional capacitada, voltada para a atenção em todos os níveis de intervenção em saúde.

O psicólogo inserido na rede pública inicialmente tinha o papel curativo e assistencialista (CARDOSO, 2002; LARA, 2006; RUTSATZ \& CÂMARA, 2006; TELLES, 2006). Os movimentos atuais mostram-se cada vez mais direcionados para a promoção e prevenção em saúde mental (FLORIANÓPOLIS, 2008; TELLES, 2006), contudo a inserção de psicólogos ainda é recente e o número desses profissionais é reduzido.

A díade mãe e bebê utilizam os mais diversos níveis de atenção-Unidades Básicas de Saúde, Ambulatórios e Hospitais - com freqüência, pois a criança necessita de diversos cuidados iniciais com a saúde, como vacinas e acompanhamento do pediatra. Além disso, crianças pequenas em decorrência da imaturidade orgânica, costumam adoecer com frequiência (MIRANDA et al., 2003). Assim, os serviços da psicologia deveriam estar fortemente inseridos nas instituições de saúde, a fim de realizar intervenções mais precoces. 
A partir disso, a promoção e prevenção em saúde mental necessita ser inserida nos diversos níveis, assim como a integração na atuação dos diversos profissionais, sempre com um olhar atento no momento inicial da relação mãe e bebê, favorecendo e prevenindo a saúde materno-infantil e promovendo práticas saudáveis nas famílias.

\section{Referências bibliográficas}

ALT, M.S. \& BENETTI, S.P.C. Maternidade e depressão: impacto na trajetória do desenvolvimento. Psicologia em estudo, v.13, n.2, p. 389394. 2008.

BARBIERI, V.; JACQUEMIM, A. \& ALVES, Z.M.M.B. Personalidade materna e resultados de crianças no psicodiagnóstico interventivo: o que significa a mãe suficientemente boa? Psico, v. 36, n. 2, p. 117-125. 2005.

BLEICHMAR, N. M. \& BLEICHMAR, C. L. A psicanálise depois de Freud. Teoria e clínica. Porto Alegre: Artes Médicas, 1992.

BORGES, M.L.S.F. Função materna e função paterna, suas vivências na atualidade. 1995. Dissertação (Mestrado em Psicologia), Universidade Federal de Uberlândia. Uberlândia.

BOWLBY, J. Uma base segura: aplicações clínicas da teoria do apego. Porto Alegre: Artes Médicas, 1989.

CARDOSO, C.L. A inserção do psicólogo no Programa de Saúde da Família. Psicologia: ciência e profissão, v. 22, n. 1, p. 2-9. 2002.

CARTER, B. \& MCGOLDRICK, M. As mudanças no ciclo de vida. Uma estrutura para a terapia familiar. Artmed: Porto Alegre, 2001.

FLORIANÓPOLIS. Protocolo de atenção à saúde mental. Disponível em: http://www.pmf.sc.gov.br/saude/programas/saudemental/protocolo_ geral jan08.pdf. Acesso em 10/2008.

LARA, A.F.L. A produção do conhecimento psicológico-psiquiátrico em saúde mental: considerações a partir de um texto exemplar. Psicologia USP, v. 17 , n. 1, p. 35-52.2006. 
LOPES, R.C.S.; OLIVEIRA, D.S.; VIVIAN, A.G.; BOHMGAHREN, L.M.C.; PICCININI, C.A. \& TUDGE, J. Sentimentos maternos frente ao desenvolvimento da criança aos 12 meses: convivendo com as novas aquisições infantis. Psicologia: teoria e pesquisa, v. 23, n. 1, p. 5-16. 2007.

MAHLER, M. As psicoses infantis e outros estudos. Artes Médicas: Porto alegre, 1983.

MIRANDA, L.P.; RESEGUE, R. \& FIGUEIRAS, A.C.M. A criança e o adolescente com problemas de desenvolvimento no ambulatório de pediatria. Jornal de pediatria, v. 79, n. 1, p. 33-42. 2003.

MONDARDO,A.H. \& VALENTINA, D.D. Psicoterapia infantil: ilustrando a importância do vínculo materno para o desenvolvimento da criança. Psicologia: reflexão e crítica, v. 11, n. 3, p. 621-630. 1998.

MURTA, S.G. Programas de Prevenção a Problemas Emocionais e Comportamentais em Crianças e Adolescentes: lições de três décadas de pesquisa. Psicologia: reflexão e crítica, v. 20, n. 1, p. 1-8. 2007.

PENNA, T.L.M. Psicoterapias breves em hospitais gerais. In Mello Filho, J. (org) Psicossomática hoje. Porto Alegre: Artes Médicas, 1992.

RUTSATZ, S.N.B. \& CÂMARA, S.G O psicólogo na Saúde Pública: trajetórias e percepções na conquista desse espaço. Alethéia, v. 23, p. 55-64. 2006.

TELLES, H.P.R.S. Infância e saúde mental: teoria, clínica e recomendações para políticas públicas. 2006. Dissertação de Mestrado. Faculdade de Saúde Pública da Universidade de São Paulo. São Paulo.

WINNICOTT, D.W. Textos selecionados: da pediatria à psicanálise. Francisco Alves: Rio de Janeiro, 1993. 